\title{
Adolescents' Self-Perception about Auditory Behavior: Agreement with Parents and Central Auditory Processing Evaluation
}

\author{
Taina Maiza Bilinski Nardez ${ }^{1}$ Laura Mochiatti Guijo ${ }^{1}$ Priscila de Araújo Lucas $^{2}$ L $^{\circledR}$ \\ Ana Cláudia Vieira Cardoso ${ }^{30}$ \\ ${ }^{1}$ Faculty of Philosophy and Sciences, Universidade Estadual Paulista \\ (UNESP), Marília, SP, Brazil \\ ${ }^{2}$ Centro Universitário de Várzea Grande (UNIVAG), Cuiabá, MT, Brazil \\ ${ }^{3}$ Department of Speech, Language and Hearing Sciences, \\ Postgraduate Program in Speech Language Pathology and \\ Audiology, Faculty of Philosophy and Sciences, Universidade \\ Estadual Paulista (UNESP), Marília, SP, Brazil \\ Int Arch Otorhinolaryngol 2022;26(1):e38-e45. \\ Address for correspondence Laura Mochiatti Guijo, PhD, Rua Guiro \\ Shimabukuro, 106, Parque das Acácias, 17.510-050, Brazil \\ (e-mail: lauramochiatti@gmail.com).
}

\begin{abstract}
Keywords

- hearing

- auditory tests

- auditory perception

- adolescents

Introduction Central auditory processing disorder (CAPD) has been diagnosed through behavioral tests. Moreover, screening tools as validated questionnaires may contribute to identify individuals at risk for this disorder, including adolescents.

Objective (1) to characterize and compare adolescents' self-perception regarding their auditory behavior with their parents' perception; (2) to verify their agreement with behavioral evaluation of central auditory processing (CAP).

Methods Cross-sectional, prospective, and descriptive study, in which 40 adolescents and 40 parents of both genders participated. All participants answered the scale of auditory behaviors questionnaire, and the behavioral evaluation of CAP was conducted with the adolescents. Findings were analyzed descriptively and inferentially, with a significance level of $5 \%(p \leq 0.05)$ and application of the following tests: Test for equality of two proportions, Chi-squared, and Kappa concordance index.

Results Most adolescents rated their auditory behavior as "low risk" for CAPD while their parents rated it as "typical." When comparing adolescents' self-perception and parents' perception about the auditory behavior with the behavioral evaluation outcome, a statistically significant difference was observed only in adolescents' selfperception. The results of the behavioral evaluation indicated that $42.5 \%$ of the adolescents showed alterations. The concordance index between adolescents' selfperception and parents' perception of auditory behavior showed a significant (minimal) difference.

Conclusion Most adolescents were able to perceive difficulties regarding their auditory behavior and characterized it as "low risk" for CAPD, but the same did not occur regarding their parents. There was agreement only between the adolescents' self-perception and their performance in the behavioral evaluation of CAP.
\end{abstract}

received

January 20, 2020

accepted

September 9, 2020

published online

March 29, 2021
DOI https://doi.org/ $10.1055 / \mathrm{s}-0040-1718966$ ISSN 1809-9777.

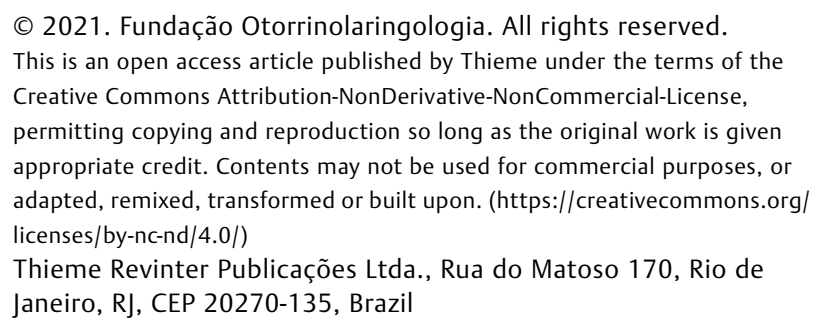

(c) 2021. Fundação Otorrinolaringologia. All rights reserved. This is an open access article published by Thieme under the terms of the Creative Commons Attribution-NonDerivative-NonCommercial-License, permitting copying and reproduction so long as the original work is given appropriate credit. Contents may not be used for commercial purposes, or adapted, remixed, transformed or built upon. (https://creativecommons.org/ licenses/by-nc-nd/4.0/) Thieme Revinter Publicações Ltda., Rua do Matoso 170, Rio de Janeiro, RJ, CEP 20270-135, Brazil 


\section{Introduction}

Central auditory processing (CAP) can be defined as "the way in which the brain recognizes and understands the sound information people listen". ${ }^{1}$ This processing encompasses auditory abilities of detection, discrimination, sound localization, speech recognition, figure-ground for verbal and nonverbal sounds, auditory closure, synthesis, simple and complex temporal ordering and temporal pattern recognition., ${ }^{2,3}$

The maturation process of the central auditory nervous system begins in the early years of life and ends in adolescence. ${ }^{4}$ Thus, adolescents are expected to be able to process auditory information properly.

Adolescence is a stage of life marked by a complex process of biopsychosocial growth and development. ${ }^{5}$ It is the moment when an individual develops his/her autonomy, leaves the family universe and decides for himself/herself, building his/her own identity. Moreover, it is at this stage that the maturation process of the central auditory nervous system is completed. ${ }^{4}$

In general, the CAP is clinically evaluated through a battery of behavioral tests to investigate some auditory abilities, such as sound localization and lateralization, auditory discrimination of verbal and nonverbal sounds, temporal auditory processing, and auditory performance with competing or degraded acoustic information, among others. ${ }^{6}$

Individuals diagnosed with central auditory processing disorder (CAPD) have the following behaviors: great difficulty hearing in noise, difficulty understanding speech, frequent repetition requests, and lack of attention and/or memory for verbal instructions. These individuals may also have reports of speech, language, literacy, attention, and academic performance disorders. Inattention and memory are often present, either as a secondary characteristic (such as fatigue associated with auditory demands) or as a primary characteristic of the impaired auditory perception. ${ }^{7}$

Studies describe that in this disorder individuals may have the following manifestations: poor school performance, reading and writing problems, social behavior disorder, difficulty discriminating sounds, difficulty in sound localization, recognizing, recording and/or understanding stimuli presented. ${ }^{8-10}$

Moreover, to identify populations at risk for CAPD, the literature has recommended the use of screening instruments to identify auditory behavior and/or performance in auditory tests. ${ }^{6,11}$

The British Society of Audiology (2018) ${ }^{7}$ recommends that the initial screening of CAP should include a wellstructured clinical history and application of validated questionnaires to both parents and teachers to identify individuals at risk for CAPD.

Questionnaires and checklists are instruments that can be used in this screening because they produce relevant information about daily life situations related to the functioning of the individual's auditory system provided by family members, teachers, and the individual himself/herself. One of these instruments is the scale of auditory behaviors (SAB) questionnaire, which was translated into European Portuguese. ${ }^{12}$ It is brief, easy to apply, and contains questions often related to the CAP.
A systematic review study demonstrated that the $S A B$ questionnaire was translated and adapted into Portuguese to be used as a screening tool for CAPD. The authors reported that among the questionnaires analyzed, the $\mathrm{SAB}$ and the children's auditory performance scale (CHAPS) were the most used in the national literature; they also determined that the population screened through these instruments was children and adolescents, emphasizing a predominance of the child population both in preschool and school age. ${ }^{13}$

In this same study, the authors highlighted that the auditory processing domains questionnaire (APDQ) was translated and validated into Brazilian Portuguese with $100 \%$ sensitivity and specificity, being the most suitable instrument for application in clinical practice and research setting. ${ }^{13}$

The auditory processing domains questionnaire (APDQ) was designed to screen auditory processing disorder. This instrument has 52 questions designed to enable parents/teachers to classify students' auditory abilities regarding auditory processing, attention, and language factors. The authors concluded the $A P Q D$ seems to be an effective screening questionnaire for individuals with CAPD because its standards on the scoring scale are useful for making appropriate clinical referrals. ${ }^{14}$

Studies developed by Kemp (2016), ${ }^{15}$ Menezes (2017) ${ }^{16}$ and Cerqueira (2018) $)^{17}$ used the SAB questionnaire as a screening tool to support the diagnosis of CAPD.

The study by Kemp ${ }^{15}$ investigated the auditory ability of 36 schoolchildren in initial grades subdivided into 2 groups: group 1 consisted of 13 children aged from 6 years to 6 years and 9 months; group 2 (G2) consisted of 23 children aged from 6 years and 11 months to 7 years and 10 months. In one of the evaluation stages, the SAB questionnaire was sent to the parents, and the analysis of items that composed the questionnaire revealed that the most frequent behaviors reported by the parents of students in G1 were: "asking to repeat things" and "disorganization," and among the parents of students in G2, they were: "not understanding well when someone speaks fast or muffled," "asking to repeat things" and "easily distracted." The author observed that the majority of the students' parents reported some behaviors that indicated difficulty in processing auditory information; however, this frequency was relatively low.

Another study ${ }^{16}$ described scores of the SAB questionnaire and verified the degree of agreement between the questionnaire and the CAP evaluation of 60 female and male children, aged 9 and 12 years old, divided into two groups: group I (GI): 30 children with learning disorder and; group II (GII): 30 children with dyslexia. The analysis of $S A B$ questionnaire showed that the average scores were similar for both groups, and the investigation of the degree of agreement between the $\mathrm{SAB}$ results and the CAP evaluation showed an accuracy of $95 \%$. It was possible to conclude that the $S A B$ questionnaire was an important predictor in the identification of CAPD.

In this study, Cerqueira ${ }^{17}$ compared and related the auditory behavior of 31 female and male individuals with stuttering, aged 7 to 26 years old, and their performance in the behavioral evaluation of CAP. The comparison of the results showed a significant difference between the final SAB score and their performance, and these findings suggest that the 
questionnaire was a good instrument in cases in which individuals had scores $\leq 45$ points, that is, they were considered at risk for CAPD, since it was confirmed in the evaluation. However, the correlation between these variables was weak.

Information provided by parents/guardians and/or teachers about an individual's auditory perception difficulties in different environments is relevant for the early identification of CAPD, especially data reported by teachers, since these individuals remain a long period of their time at school. ${ }^{18}$

Despite the existence of studies that previously investigated the parents' perception about their children's auditory behaviors during childhood, ${ }^{16,19}$ the parents' perception of adolescent populations about auditory behavior is still little investigated. In addition, considering that adolescents are able to provide feedback on their own auditory performance, it would also be relevant to investigate the self-perception of this population about the auditory behavior, thus enabling a comparison with their parents' perception.

As a hypothesis of this study, it is believed that adolescents can perceive their own difficulties related to auditory behavior and have a better perception than their parents.

Therefore, regarding the scarcity of studies on CAP with the adolescent population and the need for applicability of screening instruments, the present study aimed to: (1) characterize and compare adolescents' self-perception regarding their auditory behavior with their parents' perception; (2) verify their agreement with findings of the behavioral evaluation of CAP.

\section{Method}

This was a cross-sectional, prospective, and descriptive study, approved by the Research Ethics Committee under number 2.179.621. The data collection of this study was conducted in a private hospital, located in the city of Cuiabá, Mato Grosso, in partnership with the Faculty of Philosophy and Sciences of the São Paulo State University "Júlio de Mesquita Filho", UNESP, Marília.

Adolescents who were invited to participate in the basic audiological assessment at this location had hearing thresholds within the normal range bilaterally, based on the classification of the degree of hearing loss from the World Health Organization. ${ }^{20}$ Thus, the convenience sample consisted of 40 adolescents, being 20 female and 20 male, all regularly enrolled in elementary or high school aged 12 to 18 years old (mean age 14.82 years) and 40 parents and/or guardians.

The inclusion criteria for selection of the adolescents were: a) hearing thresholds within normal range in both ears; b) bilateral type "A" tympanometric curve, c) presence of contralateral acoustic reflex in the $500,1,000$ and $2,000 \mathrm{~Hz}$ frequencies in both ears; d) signature of the informed consent form or assent form.

The exclusion criteria were: a) to have neurological disorders; b) psychiatric disorders; c) communication and genetic syndromes reported by parents during anamnesis, which could interfere with behavioral evaluation of CAP; d) not understanding instructions needed for performing tests from the behavioral evaluation battery of CAP; e) to give up during the application of the evaluations.

Initially, the adolescents and their parents answered the anamnesis; soon after, they individually answered the scale of auditory behaviors (SAB) questionnaire, and, then, only the adolescents performed the behavioral evaluation of the CAP, composed by the following tests: speech-in-noise (SIN), synthetic sentence identification (SSI), dichotic digits test (DDT), pitch pattern test (PPT), random gap detection test (RGDT). This evaluation was performed in one session in most adolescents, but, in some cases, it took two sessions to confirm the results, especially those that presented alteration in a single test of the behavioral evaluation of CAP.

The SAB is an easy-to-apply questionnaire consisting of 12 items and scored using a 5-point Likert scale to screen auditory behavior. ${ }^{19}$ The SAB was applied to the adolescents to verify their self-perception regarding their auditory behavior and, later, to the parents to evaluate the perception about their children's auditory behavior. According to the authors of the questionnaire, the final score classifies auditory behavior as typical with a final score $\geq 46$ points, low-risk behavior for auditory processing disorder values between 31 and 45 points, and high-risk behavior for auditory processing disorder is defined by a score $\leq 30$ points ( - Fig. 1 ).

The test battery of the CAP evaluation was performed in an acoustic booth, using a 2-channel audiometer AD229-e, which was coupled to a computer, and it was applied by an audiologist.

The SIN test evaluates the auditory ability of closure, being a monotic task. A list of 25 monosyllables with a competitive message of white noise was displayed, in which the competitive message was in a signal-to-noise ratio at $+10 \mathrm{~dB}$, monaurally, and the main message was at an intensity of $40 \mathrm{dBSL}$. The adolescents were instructed to repeat the monosyllables orally. The reference criterion adopted as normality was to reach several correct answers ( $\geq 70 \%)$ in both ears or a difference between the percentage of SRI and SIN results $>20 \%$, considering the same ear. ${ }^{21}$

The SSI test with competitive message is used to evaluate the auditory ability of figure-ground for verbal sounds and the association of auditory and visual stimuli. This test consists of 10 sentences, displayed simultaneously to a competitive message composed by a story. The stimuli were displayed monaurally in two signals to noise ratios (SNR), 0 and $-10 \mathrm{~dB}$, and the main message (phrase) was displayed at an intensity of 40 dBSL. The adolescent was positioned in front of a poster containing the sentences, and for each sentence heard, he or she should point to the corresponding phrase on the poster. The reference criterion adopted for normality was to reach several correct answers ( $\geq 70 \%$ ) for the signal-to-noise ratio $-10 \mathrm{~dB} .^{21}$

Another test applied was the DDT, which evaluates the figure-ground ability for verbal sounds. The test consists of displaying 4 lists of 20 items each, in which each item containing 4 digits, selected from numbers 1 to 9 . In this study, only the binaural integration stage was applied at an intensity of $50 \mathrm{dBSL}$. The adolescent was instructed to orally repeat the four digits displayed, regardless of their presentation order. The reference criterion adopted for normality was to reach several correct answers $(\geq 95 \%)$ in both ears. ${ }^{21}$ 
Name:

Date of birth: Schooling:

Signature of the subject or responsible:

Date 1

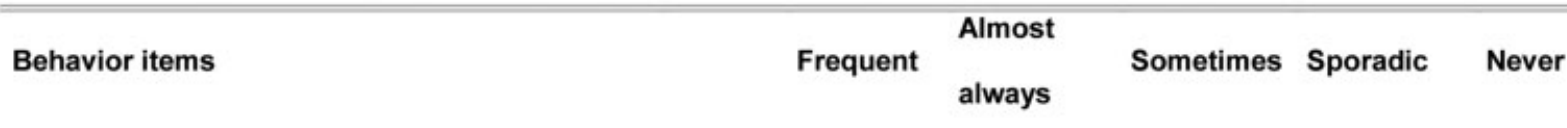

\section{Difficulty listening or understanding in noisy} environment

2. Does not understand well when someone speaks fast or "muffled"

3. Difficulty following oral instructions

4. Difficulty identifying and discriminating speech sounds

5. Inconsistency of response to auditory information

6. Poor reading ability

7. Ask to repeat things

8. Easily distracted

9. Academic or learning difficulties

10. Short Attention Period

11. Dream awake, seem inattentive

12. Disorganized

Source: Nunes; Pereira e Carvalho (2013).
1

1

1

1

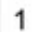

1

1

1

1

1

1

1
2

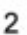

2

2

2

2

2

2

2

2

2

2
4

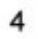

4

4

4

4

4

4

4

4

4
5

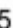

5

5

5

5

5

5

5

Fig. 1 Scale of auditory behaviors (SAB). Fonte: Nunes; Pereira e Carvalho (2013).

The PPT evaluates the temporal ordering ability. In this study, the PPS (adult version) proposed by Auditec, Inc. (St. Louis. MO, USA) (1997) was applied because this version shows potential to identify normality in the temporal ordering ability. ${ }^{22}$ This test consists of 30 sequences of 3 tones, which can be low frequency $(880 \mathrm{~Hz})$ or high frequency $(1,430 \mathrm{~Hz})$. Each tone has duration of 200 milliseconds (ms), with an interval of $150 \mathrm{~ms}$ between tones and 7 seconds between sequences. The test allows six combinations between the low $(\mathrm{L})$ and high $(\mathrm{H})$ stimuli: HHL, HLH, HLL, LLH, LHL, and LHH. Prior to the beginning of the test, the patient underwent a training to ensure the perception of the difference between tones to be tested and the understanding of the task to be performed. The test was binaurally displayed at an intensity of $50 \mathrm{dBSL}$. Participants were instructed to name the stimuli in the same presentation order. The normality criterion adopted was to reach a percentage of correct answers $\geq 90 \% .{ }^{23}$ Finally, the
RGDT was applied to evaluate temporal resolution ability. The test consists of displaying pure tones paired with short silent intervals ranging from 0 to $40 \mathrm{~ms}$ randomly presented. The interval detection threshold is considered to be the shortest interval from which the individual is able to consistently identify the occurrence of two stimuli. This test was displayed binaurally at an intensity of $50 \mathrm{dBSL}$. The patient was instructed to lift the finger each time he or she heard one or two stimuli. The normality criterion adopted was values $\leq 10 \mathrm{~ms}^{24}$

The CAP evaluation was classified as normal or altered based on the criteria established by the Diagnostic Forum of the 31st International Audiology Meeting, ${ }^{25}$ according to which alteration in only one physiological mechanism, being observed the conditions of the test application regarding the individual's attention and the compatibility of the alteration with the patient's history and test/retest in the case of very small alterations. 
To compare adolescents' self-perception of their auditory behavior, parents' perception of their children's auditory behavior, and to analyze the relationship between the adolescents' performance in each test and the final outcome of the behavioral evaluation of the CAP, the test for equality of two proportions was applied. To compare adolescents' selfperception with parents' perception about the auditory behavior, the Chi-squared test and the Kappa concordance index were applied to measure the degree of agreement between these variables.

To verify the relationship between adolescents' self-perception and parents' perception regarding the auditory behavior and the performance in the behavioral evaluation of the CAP (normal or altered), the Chi-squared test was applied. The significance level adopted was $5 \%(p \leq 0.05)$ and, for the Kappa concordance index, the following values were considered: $<0.200$ negligible; between 0.210 and 0.400 minimum; between 0.410 and 0.600 regular; between 0.610 and 0.800 good and; above 0.810 great.

\section{Results}

The analysis of the SAB questionnaire answered by the adolescents showed that the auditory behavior of most participants was classified as "low risk," but this difference was significant in relation to "high risk" (-Table $\mathbf{1}$ ).

Regarding the parents' perception, $65 \%$ of parents rated the adolescents' auditory behavior as "typical." Comparison between the other classifications, "low risk" and "high risk," showed a significant difference (-Table 2 ).

When analyzing the agreement index between adolescents' self-perception and parents' perception in relation to the auditory behavior, a significant difference was found. However, as the agreement value was minimal, it should be disregarded (- Table 3 ).

When comparing adolescents' self-perception with their parents' perception in relation to the auditory behavior with performance of the behavioral evaluation of the CAP, a significant difference was found only for adolescents' selfperception (-Table 4).

- Table 5 shows the classification of adolescents' performance in the tests that comprised the behavioral evaluation of CAP. It was observed that in the DD, SIN, SSI, and RGDT, there was a higher percentage of normal results and this difference was statistically significant. However, the PPS showed a higher percentage of altered results.

Table 1 Characterization of the classification of auditory behavior based on adolescents' self-perception

\begin{tabular}{|l|l|l|l|}
\hline Auditory behavior & $\mathrm{N}$ & $\%$ & $P$-value \\
\hline High risk & 1 & $2.5 \%$ & $<\mathbf{0 . 0 0 1 ^ { * }}$ \\
\hline Low risk & 23 & $57.5 \%$ & Ref. \\
\hline Typical & 16 & $40.0 \%$ & 0.117 \\
\hline
\end{tabular}

Abbreviations: N, casuistry; Ref, reference.

Test for equality of two proportions

*Significance level $p \leq 0.05$
Table 2 Characterization of the classification of auditory behavior based on parents' perception

\begin{tabular}{|l|l|l|l|}
\hline Auditory behavior perception & $\mathbf{N}$ & $\mathbf{\%}$ & P-value \\
\hline High risk & 3 & $7.5 \%$ & $<\mathbf{0 . 0 0 1}^{*}$ \\
\hline Low risk & 11 & $27.5 \%$ & $<\mathbf{0 . 0 0 1}$ \\
\hline Typical & 26 & $65.0 \%$ & Ref. \\
\hline
\end{tabular}

Test for equality of two proportions Caption: N, casuistry; Ref, reference

*Significance level $p \leq 0.05$

Table 3 Concordance Index between adolescents' selfperception and parents' perception about auditory behavior

\begin{tabular}{|l|l|}
\hline \multicolumn{2}{|l|}{ Adolescents' self-perception versus parents' perception } \\
\hline Kappa & 0.397 \\
\hline$P$-value & $0.001^{*}$ \\
\hline
\end{tabular}

Kappa concordance index

*Significance level $p \leq 0.05$

\section{Discussion}

The application of well-designed questionnaires that have questions specifically related to auditory behaviors may assist in the referral of at-risk populations to specialized evaluation and, consequently, assist the diagnostic process of CAPD. $^{7}$

In this study, the SAB questionnaire was applied as a screening instrument, with the purpose of evaluating adolescents' self-perception regarding their auditory behavior and also their parents' perception. Assuming that self-perception refers to the manner in which an individual understands his/her own attitudes based on his/her behavior in certain situations.

Considering the classification of auditory behavior based on the SAB score ${ }^{19}$ and the adolescents' self-perception findings in relation to their auditory behavior, it was observed that adolescents had an average score of 43.9 points, which corresponds to the classification "low risk" for CAPD.

It is also worth mentioning that $57.5 \%$ of the adolescents in this study classified their behavior as "low risk." These results suggest that most adolescents were able to identify, in their daily routine, situations in which they had difficulty understanding information aurally received, especially in background noise.

Regarding the parents' perception of the auditory behavior of their adolescents, it was observed that the average score of the SAB questionnaire answered by the parents was 46.4 points, which corresponds to "typical" auditory behavior. $^{19}$ It is also highlighted that $65 \%$ of parents rated their adolescents' auditory behavior as "typical."

Findings of adolescents' self-perception and their parents' perception are relevant, since no previous studies that used a screening instrument to characterize adolescents' auditory behavior were found in the literature. 
Table 4 Comparison between adolescents' self-perception and parents' perception about the auditory behavior and the adolescents' performance in the behavioral evaluation of central auditory processing

\begin{tabular}{|c|c|c|c|c|c|c|c|c|}
\hline \multicolumn{2}{|l|}{ Behavioral evaluation outcome of CAP } & \multicolumn{2}{|c|}{ Altered } & \multicolumn{2}{|c|}{ Normal } & \multicolumn{2}{|c|}{ Total } & \multirow{2}{*}{$\begin{array}{c}P \text {-value } \\
0.005^{*}\end{array}$} \\
\hline Auditory behavior self-perception (adolescents) & High risk & $\begin{array}{c}\mathrm{N} \\
1\end{array}$ & $\begin{array}{l}\% \\
5.9 \% \\
\end{array}$ & $\frac{N}{0}$ & $\begin{array}{l}\% \\
0.0 \%\end{array}$ & $\begin{array}{c}\mathrm{N} \\
1\end{array}$ & $\begin{array}{l}\% \\
2.5 \% \\
\end{array}$ & \\
\hline & Low risk & 14 & $82.4 \%$ & 9 & $39.1 \%$ & 23 & $57.5 \%$ & \\
\hline & Normal & 2 & $11.8 \%$ & 14 & $60.9 \%$ & 16 & $40.0 \%$ & \\
\hline \multirow[t]{3}{*}{ Auditory behavior perception (parents) } & High risk & 1 & $5.9 \%$ & 2 & $8.7 \%$ & 3 & $7.5 \%$ & \multirow[t]{3}{*}{0.058} \\
\hline & Low risk & 8 & $47.1 \%$ & 3 & $13.0 \%$ & 11 & $27.5 \%$ & \\
\hline & Normal & 8 & $47.1 \%$ & 18 & $78.3 \%$ & 26 & $65.0 \%$ & \\
\hline
\end{tabular}

Abbreviations: $\mathrm{N}$, casuistry; CAP, central auditory processing.

Chi-square test

*Significance level $p \leq 0.05$

Table 5 Classification of the adolescents' performance, normal or altered, in the tests that composed the behavioral evaluation of central auditory processing

\begin{tabular}{|c|c|c|c|c|c|}
\hline \multirow[t]{2}{*}{ Classification of the behavioral evaluation of CAP } & \multicolumn{2}{|c|}{ Altered } & \multicolumn{2}{|c|}{ Normal } & \multirow[t]{2}{*}{$P$-value } \\
\hline & $\mathrm{N}$ & $\%$ & $\mathrm{~N}$ & $\%$ & \\
\hline DDT & 2 & $5.0 \%$ & 38 & $95.0 \%$ & $<0.001^{*}$ \\
\hline SIN & 2 & $5.1 \%$ & 37 & $94.9 \%$ & $<0.001^{*}$ \\
\hline SSI & 5 & $12.5 \%$ & 35 & $87.5 \%$ & $<0.001^{*}$ \\
\hline PPS & 16 & $40.0 \%$ & 24 & $60.0 \%$ & 0.074 \\
\hline RGDT & 2 & $5.0 \%$ & 38 & $95.0 \%$ & $<0.001^{*}$ \\
\hline
\end{tabular}

Abbreviations: CAP, central auditory processing; N, casuistry; DDT, dichotic digits test; SIN, speech in noise; SSI-synthetic sentence identification; PPS, pitch pattern test; RGDT, random gap detection test.

Test for equality of two proportions

*Significance level $p \leq 0.05$

The analysis of agreement between adolescents' selfperception and parents' perception regarding auditory behavior was minimal, and thus was disregarded.

In the reviewed literature, there are few studies that investigated the agreement between adolescents' self-perception and parents' perception regarding auditory behavior. However, a study which aimed to compare the students' and parents' responses using a questionnaire found similarity in the results between the parents' and students' responses.

Thus, the authors suggested that, based on the findings, there was greater reliability, so that the questionnaire could be applied only to the student. ${ }^{26}$ The findings of this study differ from those of a previous study, ${ }^{26}$ most likely due to the different population's age range and the parents' attention level in relation to the school difficulties shown by their children.

A study investigated children's hearing complaints and parents' opinions about their children's hearing and concluded that the children's hearing complaints were prevalent and relevant, but most of them had never undergone an audiological assessment and most parents were unaware of the hearing complaints reported by their children ${ }^{27}$.

The results of the present study showed the importance of valuing the individual's self-perception regarding his/her auditory behavior in the diagnosis process of CAPD, especially in the adolescent population, since they were able to identify and report their difficulties in daily life activities, both at home and at school. Possibly, due to the maturation process of the central auditory nervous system is complete in the adolescence stage.

In terms of behavioral evaluation of the CAP, the analysis of the adolescents' performance showed that $42.5 \%$ had alterations in this evaluation. The analysis by test showed that the adolescents had performance compatible with normality in most tests (DD, SIN, SSI ipsilateral competing message, and RGDT), and this difference was significant. The only test in which $40 \%$ of adolescents had altered performance was the PPT.

This high rate of alteration (42.5\%) in the behavioral evaluation of the CAP is probably due to the fact that the present study adopts the criterion established by the Diagnostic Forum of the 31st International Audiology Meeting ${ }^{25}$ as reference, which considers alteration in only one test. Thus, it is worth mentioning that the adolescents who had alterations in a single test were retested and confirmed, and there was confirmation of such findings in this research.

The PPT evaluates the temporal ordering auditory ability, which has currently been extensively investigated due to its importance for speech perception. This auditory ability refers to the processing of two or more acoustic stimuli according to the order of occurrence, in a certain time 
interval. $^{28}$ Thus, any inability to sequence the order of occurrence of sound events can impair the perception of verbal and nonverbal sounds, the understanding of information about things, places and events around us, as well as the perception of prosodic aspects of speech and reading. ${ }^{29-31}$

A study that verified the relationship between academic performance and auditory temporal aspects of adolescents in the 6th grade of elementary school showed that the results of temporal tests were not influenced by the variables: gender, age, musicalization, and manual preference; However, a significant difference was observed between the speechlanguage management variable and the findings obtained in the GIN test. Regarding the academic performance test, it was observed that the subtests that had the greatest influence on the duration pattern (DP) and pitch pattern tests were writing, followed by reading and arithmetic. The researchers concluded that there is a correlation between academic performance and auditory temporal aspects, specifically for temporal ordering ability. ${ }^{31}$

A study by Machado ${ }^{32}$ investigated and analyzed the CAP and some neuropsychological aspects of a group of adolescents with chronic non cholesteatomatous otitis media and a control group. The results showed a significant difference for the averages obtained between the two groups in all CAP tests applied, including the PPT. This study concluded that non-cholesteatomatous chronic otitis media had an influence on both CAP evaluation and attention, memory, and executive function subtests.

Another study compared the adolescents' performance exposed and not exposed to metallic mercury in the behavioral tests of the CAP. The analysis of the results showed a significant difference between groups, and the group of adolescents exposed to mercury underperformed in the majority of the applied tests, especially in the PPT, DP and ADDT. ${ }^{33}$

The findings of the present study corroborate the literature regarding the higher occurrence of alteration in temporal ordering auditory ability for the adolescent population. In the current study, the adolescent's self-perception was compared with his/her performance in the auditory processing evaluation and the results showed a significant difference between adolescents' self-perception and their performance in the PPT, DD, and SSI - ipsilateral competing message. However, there were no studies in the international and national literature comparing the self-perception and performance of adolescents in the CAP evaluation.

However, a national study analyzed the students' performance in the simplified auditory processing test and compared it with a self-perception questionnaire based on the SAB. These questions were modified to a more accessible and direct language to facilitate the participants' understanding. The analysis of the results showed that worse performance for both the SAP test and the self-perception questionnaire (SAB) occurred in the group of children who had school difficulties. From the correlation analysis, the authors concluded that the SAP test and the self-perception questionnaire should be used as complementary diagnostic methods. ${ }^{26}$

The findings of the present study also suggest that the SAB questionnaire was a good screening instrument when ap- plied to adolescents and that self-perception of this population should be valued in the diagnostic process.

To verify one of the hypotheses of this study, the authors compared adolescents' self-perception and parents' perception regarding the auditory behavior and performance in the behavioral evaluation of the CAP. A significant difference was observed between the adolescents' self-perception and their performance in the CAP evaluation, since the 15 adolescents who had alterations in the behavioral evaluation of the CAP classified their auditory behavior as "high risk" (5.9\%) and "low risk" (82.4\%) for CAPD. It is also noteworthy that the same did not occur in relation to the parents' perception.

The disagreement between findings of the adolescents' self-perception and their parents' perception can be explained due to the fact that self-perception is an individualized process, characterized by a unique perception, and that cannot be measured equally by the individuals around them, for example parents and/or teachers.

However, a study whose objective was to investigate the auditory abilities of European Portuguese children and verify their correlation with the scale of auditory behaviors (SABs) score answered by parents, concluded that this correlation exists. ${ }^{19}$

A study conducted with 60 Brazilian children diagnosed with learning disabilities and dyslexia had as one of its specific objectives to verify the degree of agreement between the SAB questionnaire answered by parents and the CAP evaluation. In this study, a 95\% agreement between the questionnaire score and the result of the behavioral evaluation of the CAP was found. ${ }^{16}$

In the aforementioned studies, there was an agreement between the parents' perception, obtained through the SAB questionnaire and the performance in the behavioral evaluation of the CAP. However, such finding did not occur in this study.

In this study, the lack of agreement between parents' perception and performance in the behavioral assessment of CAP may be explained by the average age of adolescents, which was 14.82 years. In the other studies, the participants' age was lower, which probably made parents more attentive to their children's auditory difficulties.

Finally, we believe in the design of new studies with greater investment of researchers in non-invasive evaluations that provide evidence of central auditory nervous system involvement in specific language and learning disorders in the adolescent population; in validating questionnaires that can be used as screening instruments for CAPD; in the inclusion of screening instruments in clinical routine of the audiologist for the diagnosis of CAPD; and in the inclusion of temporal processing tests in the behavioral test battery of the CAP.

Absence of a correlation between adolescents' self-perception and parents' perception with the adolescents' school performance is highlighted as a limitation of this study. Thus, new study designs with the adolescent population are needed to correlate these aspects.

\section{Conclusion}

Most adolescents were able to perceive difficulties regarding their auditory behavior and characterized it as "low risk" for 
CAPD but the same did not occur with their parents. There was agreement only between the adolescents' self-perception and their performance in the behavioral evaluation of the CAP.

\section{Conflict of Interests}

The authors have no conflict of interests to declare.

\section{References}

1 Boscariol M, Andre KD, Feniman MR. Crianças com fissura isolada de palato: desempenho nos testes de processamento auditivo. Rev Bras Otorrinolaringol 2009;75(02):213-220

2 Canadian Audiologist CAPD Guidelines. 2014 Disponível em: http://canadianaudiologist.ca/capd-guidelines/. Accessed April 05, 2018.

3 Pereira LD. Sistema auditivo e desenvolvimento das habilidades auditivas. In: Ferreira LP, Befi-Lopes DM, Limonge SCO. (org.) Tratado de Fonoaudiologia. São Paulo: Roca; 2004:547-552

4 Schettini RC, Rocha TCM, Almeida LDM. Distúrbio do Processamento Auditivo: o que é?: orientações aos pais e professores 2 ed. Ribeirão Preto: Book Toy; 2011

5 BRASIL - Ministério da Saúde Marco legal: saúde, um direito de adolescentes [Internet] Brasília: Ministério da Saúde. 2007 Available at: http://www.adolescencia.org.br/upl/ckfinder/files/pdf/ marco_legal.pdf. Accessed Jan 10, 2019.

6 ASHA AMERICAN SPEECH-LANGUAGE-HEARING ASSOCIATION: (Central) Auditory processing disorders - Technical report [Internet] American Speech-Language-Hearing Association. 2005 Available at: < http://www.asha.org/policy >. Accessed April 05, 2018.

7 BSA British Society of Audiology Position Statement and Practice Guidance Auditory Processing Disorder (APD). 2018Disponível em: <. http://www.thebsa.org.uk/>. Accessed April 05, 2018.

8 Keith RW, Pensak ML. Central auditory function. Otolaryngol Clin North Am 1991;24(02):371-379

9 Martins JS, Pinheiro MMC, Blasi HF. A utilização de um software infantil na terapia fonoaudiológica de Distúrbio do Processamento Auditivo Central. Rev Soc Bras Fonoaudiol 2008;13(04): 398-404

10 Pereira LD. Introdução ao Processamento Auditivo Central. Bevilacqua, Maria Cecília (org.). Tratado de Audiologia São Paulo: Santos; 2011:279-91

11 AMERICAN ACADEMY OF AUDIOLOGY CLINICAL PRACTICE GUIDELINNES Diagnosis, treatment and management of children and adults with central auditory processing disorder [Internet] American Academy of Audiology. 2010 Available at: <https:// www.audiology.org/publications/guidelines-and-standards $>$. Accessed April 05, 2018.

12 Nunes CL. A avaliação do processamento auditivo em crianças de 10 a 13 anos: sua função como indicador da perturbação da comunicação e do desempenho académico [tese]. Braga: Universidade do Minho; 2012:253

13 Volpatto FL, Rechia IC, Lessa AH, Soldera CLC, Ferreira MIDDC, Machado MS. Questionnaires and checklists for central auditory processing screening used in Brazil: a systematic review. Rev Bras Otorrinolaringol (Engl Ed) 2019;85(01):99-110

14 O'Hara B, Mealings K. Developing the auditory processing domains questionnaire (APDQ): a differential screening tool for auditory processing disorder. Int J Audiol 2018;57(10):764-775
15 Kemp AAT. Processamento auditivo central em escolares das séries iniciais de alfabetização [dissertation]. Marília: Faculdade de Filosofia e Ciências, Universidade Estadual Paulista2016:72

16 Menezes AAVB. Processamento Auditivo em crianças com Transtorno de Aprendizagem e Dislexia [dissertation]. Marília: Faculdade de Filosofia e Ciências, Universidade Estadual Paulista2017:80

17 Cerqueira AV. Perfil das habilidades auditivas em indivíduos com gagueira. 2018 [dissertation]. Marília: Faculdade de Filosofia e Ciências, Universidade Estadual Paulista 201880

18 Bellis TJ. Central Auditory Screening and Assessment Procedures. Assessment and management of central auditory processing disorders in the educational setting: from science to practice New York: Thomson Delmar Learning; 2003:142-191

19 Nunes CL, Pereira LD, de Carvalho GS. Scale of Auditory Behaviors e testes auditivos comportamentais para avaliação do processamento auditivo em crianças falantes do português europeu. CoDAS 2013;25(03):209-215

20 WHO WORLD HEALTH ORGANIZATION: Grades of hearing impairment [Internet] World Health Organization. 2014 Available at: <https://www.who.int/pbd/deafness/hearing_impairment_grades/en/>. Accessed May 15, 2017.

21 Pereira LD, Schochat E. Testes auditivos comportamentais para avaliação do processamento auditivo central. São Paulo: Pró Fono, 2011

22 Gois M, Biaggio EPV, Bruckmann M, Pelissari I, Bruno RS, Garcia MV. Temporal ordering ability and level of specificity at different pure tone tests. Audiol Commun Res 2015;20(04):293-299

23 Auditec Evaluation manual of pitch pattern sequence and duration pattern sequence Missouri; 1997

24 Ziliotto K, Pereira LD. Random gap detection test in subjects with and without APD. Trabalho apresentado no 17th American Academy of Audiology - Annual Convention and Exposition. Washington, DC - EUA; 2005:30

25 ABA ACADEMIA BRASILEIRA DE AUDIOLOGIA Fórum: Diagnóstico Audiológico. $31^{\circ}$ Encontro Internacional de Audiologia. 2016. Available at:<http://www.audiologiabrasil.org.br/31eia/pdf/ forum_f.pdf $>$. Accessed Feb 22, 2018.

26 Souza IMP, Carvalho NG, Plotegher SDCB, Colella-Santos MF, Amaral MIR. Auditory processing screening: contributions of the combined use of questionnaire and auditory tasks. Audiol Commun Res $2018 ; \cdots: 23$

27 Knobel KAB, Lima MCMP. Are parents aware of their children's hearing complaints? Rev Bras Otorrinolaringol (Engl Ed) 2012;78 (05):27-37

28 Pichora-Fuller MK, Souza PE. Effects of aging on auditory processing of speech. Int J Audiol 2003;42(Suppl 2):S11-S16

29 Pina VMG. Processamento temporal: sua importância para a aprendizagem da leitura. Constr Psicopedag 2012;20(20):20-34

30 Shinn JB. Temporal processing: the basics. Hear J 2003;56:52

31 Terto SSM, Lemos SMA. Aspectos temporais auditivos em adolescentes do $6^{\circ}$ ano do ensino fundamental. Rev CEFAC 2013;5 (02):271-286

33 Machado MS. Otite média crônica: impacto no processamento auditivo e aspectos neuropsicológicos de adolescentes. [dissertation]. Porto Alegre (RS): Universidade Federal do Rio Grande do Sul2017:102

33 Dutra MDS, Monteiro MC, Camara VM. Avaliação do processamento auditivo central em adolescentes expostos ao mercúrio metálico. Pró-Fono Revista de Atualização Científica, Barueri 2010;22(03):339-344 